\title{
Human arylamine $N$-acetyltransferase 1 (NAT1) as a target of chemotherapeutic drugs in breast cancer: cisplatin as a model
}

\author{
Nilusha Ragunathan ${ }^{1}$, Julien Dairou ${ }^{1,2}$, Benjamin Pluvinage ${ }^{1}$, Marta Martins ${ }^{1}$, Jean-Marie \\ Dupret $^{1,2}$ and Fernando Rodrigues-Lima ${ }^{1,2}$
}
${ }^{1}$ Universite Paris Diderot-Paris 7, Laboratoire de Cytophysiologie et Toxicologie Cellulaire (EA1553), 75013, Paris, France; ' UFR des Sciences du Vivant, Universite Paris Diderot - Paris 7, 75013, Paris, France

PharmSight on Ragunathan $\mathrm{N}$, et al. Identification of the xenobiotic-metabolizing enzyme arylamine Nacetyltransferase 1 (NAT1) as a new target of cisplatin in breast cancer cells: molecular and cellular mechanisms of inhibition. Mol Pharmacol 2008;73:1761-8.

\begin{abstract}
Human arylamine $N$-acetyltransferase 1 (NAT1) is a phase II xenobiotic-metabolizing enzyme (XME) involved in the biotransformation of many aromatic amines and heterocyclic amines. This XME is known to play important roles in both the detoxication and/or bioactivation of numerous drugs and carcinogens. NAT1 is a polymorphic enzyme with a large tissue distribution. NAT1 polymorphisms and activity have been extensively studied because of its potential role in the biotransformation of important carcinogens. Several recent studies suggest that NAT1 may have a role in breast cancer progression. Indeed, this XME has been shown to affect the growth and drug resistance of breast cancer cells and appears to be a marker in human estrogen receptor positive breast cancer. Here we provide an overview of our recently published results indicating that NAT1 is a new target of the anticancer drug cisplatin in breast cancer cells. Moreover, these results are discussed in light of the data showing inhibition of human NAT1 and its mouse orthologue by natural and synthetic estrogens.
\end{abstract}

NAT1 is one of the two polymorphic human XME that biotransforms various aromatic and heterocyclic amines through their acetylation (1). This enzymatic reaction can lead either to detoxification (mainly through $\mathrm{N}$-acetylation) or to

Received 09/10/08; accepted 12/22/08

Correspondence: Dr. Fernando Rodrigues-Lima, Laboratoire de Cytophysiologie et Toxicologie Cellulaire

(EA 1553) Univ Paris Diderot-Paris 7, 75013, Paris,

France. Phone: 33153278336 bioactivation (through O-acetylation) (1). Several NAT1 substrates are therapeutic drugs or environmental carcinogens $(1,2)$. In addition, NAT1 $N$-acetylates the folate catabolite $\mathrm{p}^{-}$ aminobenzoylglutamate (3). This suggests a role of this XME in folate metabolism and in related congenital or malignant diseases (4). Contrary to the NAT2 isoform, NAT1 is ubiquitously expressed $(5,6)$. The NAT1 gene is located in chromosome 8 at $8 \mathrm{p} 21^{-}$ 22 , a region reported to be deleted in many cancers (7).

Changes in the $N^{-}$and/or $O$-acetylation of these aromatic compounds have been linked to carcinogenesis $(1,8)$. The balance between $\mathrm{N}^{-}$and $\mathrm{O}^{-}$ acetylation depends on several factors, in particular on NAT activity. Several polymorphisms affecting NAT1 enzyme activity have been reported (9). These inter-individual variations have been implicated in modulating susceptibility to adverse drug reactions and to various diseases, including cancer (9). In addition, NAT1 activity is now known to be influenced by environmental factors such as certain aromatic amine substrates or biological oxidants $(10-14)$. NAT1 is thus regulated at both genetic and environmental levels and the functions of this XME may be linked to carcinogenesis (15).

Several lines of recent evidence further support a role for NAT1 in breast cancer. Indeed, several microarray and proteomic studies indicate that NAT1 is highly expressed in estrogen receptor positive breast cancer (16). NAT1 gene is one of the ten most highly expressed genes in estrogenresponsive-positive tumors. The results of these studies have recently been reviewed by Wakefield et 
al., (16) and are available through the Oncomine database (http://www.oncomine.org/). Moreover, overexpression of NAT1 in normal breast luminal epithelial cells induced two of the hallmark traits of cancer, i.e., enhanced growth and resistance to certain therapeutic cytotoxic drugs used in cancer treatment (drugs such as etoposide) (17). In addition, recent studies from Minchin's group (18) have shown that NAT1 is induced by androgens in human prostate cancer cells with possible implications for cancer risk (18). The increasing evidence for an association of NAT1 with carcinogenesis, in particular with breast cancer, suggests that this XME could be targeted for breast cancer therapy.

We recently reported evidence showing that human NAT1 is a target of cisplatin (cisdiaminedichloroplatinumII) (19) (Fig. 1). This drug is one of the most important chemotherapeutic compounds used in the management of various human malignancies (20). The efficacy of cisplatin against several breast cancer cells in vitro has recently highlighted the potential use of such drugs in the clinic for breast cancer (20). It has been known for a long time that the cytotoxic/cytostatic effects of cisplatin are mainly due to its ability to form intrastrand and interstrand cross-links within DNA, leading to altered DNA replication, cell growth and apoptosis. However, evidence suggests that cisplatin may also function through additional mechanisms not related to DNA-binding (21). In fact, only around $1 \%$ of cisplatin is bound to DNA and most of the drug is available for interactions with nucleophilic sites on other biological molecules. Therefore it is likely that some of the pharmacological and/or toxicological effects of cisplatin are due to reaction with cellular macromolecules, in particular proteins (21). Indeed, the function of several key enzymes has been reported to be impaired by cisplatin. These enzymes include DNA polymerase (22), caspases 3 and 8 (23), and topoisomerase II (24).

We found that a short exposure of two human breast cancer cell lines, MCF-7 and MDA-MB-231, to cisplatin at pharmacologically relevant levels could impair the endogenous functions of NAT1. When mice were exposed to cisplatin at clinicallyrelevant concentrations $(<400 \mu \mathrm{M})$ significant inhibition (ranging from 25 to $50 \%$ inhibition) of endogenous NAT1 activity was noted in liver, kidney and blood. Biochemical and enzymatic studies using recombinant human NAT1 enzyme provided further insight into the putative molecular basis for the impairment of human NAT1 by cisplatin in vitro

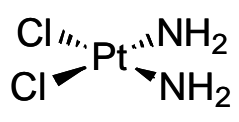

cisplatin

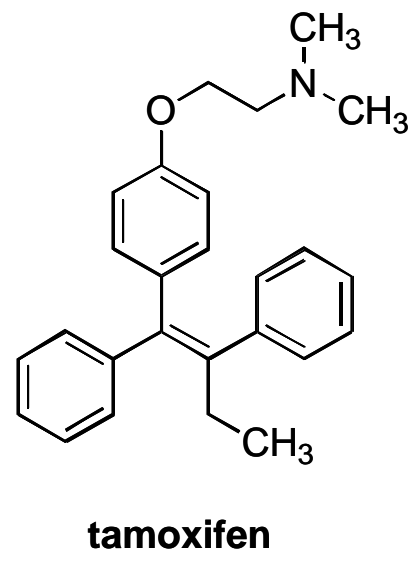

Figure 1. Chemical structures of cisplatin and tamoxifen.

and in vivo. We found that the inhibition of the enzyme by cisplatin was due to the formation of an irreversible drug-adduct with the active-site cysteine residues of NAT1. The second-order rate constant for the formation of this adduct and the subsequent inhibition of the enzyme were determined to be 700 $\mathrm{M}^{-1}$. $\min ^{-1}$. This parameter indicated that the reaction of cisplatin with NAT1 was rapid. So far, this rate constant appears to be the maximum reported for a reaction between biological molecule and cisplatin. Indeed, the second-order rate constant of cisplatin for DNA reaction of cisplatin is around $125 \mathrm{M}^{-1}$. $\min ^{-1}$. Reduced glutathione and metallothioneins, two of the most important scavengers of cisplatin in cells, are known to react with this drug with second-order rate constants of $1.6 \mathrm{M}^{-1} \cdot \mathrm{min}^{-1}$ and $38 \mathrm{M}^{-1} \cdot \mathrm{min}^{-1}$, respectively. These data may explain why cisplatin reacts with cellular NAT1 despite the presence of theses scavengers at high concentrations in cells (around $2 \mathrm{mM}$ ). The reactive nature of the active-site cysteine residue of NAT1 likely accounts for the high reactivity of cisplatin for this enzyme and its subsequent inactivation. Impairment of caspase 3 and 8 functions by cisplatin have been shown to rely on a similar mechanism (23). Although our data do not demonstrate that alteration of NAT1 functions in cells contributes to the therapeutic effect of cisplatin, our results emphasize the putative link between NAT1 and breast cancer. 
Our findings must also be discussed in light of recent studies aimed at understanding the role of NAT1 in breast carcinogenesis. Indeed, the Edith Sim's group (16) has clearly shown that NAT1 could be a marker in human estrogen receptor positive breast cancer (16). Using mouse Nat2 as a model (murine NAT2 is the orthologue of human NAT1), these authors confirmed previous studies (25) showing that tamoxifen (Fig. 1), an important chemotherapeutic drug which is used against breast and prostate cancers, impairs the activity of NAT1 (26). Other estrogenic compounds such as 17hydroxy- $\beta$-estradiol were also found to inhibit murine NAT2 enzyme. The mechanisms underlying the impairment of NAT1 by tamoxifen have not been reported. The mouse models that are currently being studied are likely to provide more information on the contribution of NAT1 enzyme to cancer (26). Our recent finding that cisplatin inhibits human NAT1 in breast cancer cells coupled with the recent observations that this XME may contribute to altered cell growth and may serve as a marker in estrogen receptor positive breast cancer, collectively emphasize the need to study the mechanisms controlling NAT1 functions.

\section{Acknowledgments}

Work in the laboratory of authors is supported by grants from ARC (Association pour la Recherche sur le Cancer), AFM (Association Française contre les Myopathies), Association Rétina France, AFSSET (Agence Française de Sécurité Sanitaire de l'Environnement et du Travail), Ministère de l'Enseignement Supérieur et de la Recherche, Chancellerie des Universités de Paris (Leg Poix), Ministère des Affaires Etrangères et Européennes (Contrat Alliance) and Caisse d'Assurance Maladie des Professions Libérales de Province.

\section{References}

1. Hein D. Molecular genetics and function of NAT1 and NAT2: role in aromatic amine metabolism and carcinogenesis. Mutat Res 2002;506-507:65-77.

2. Badawi AF, Hirvonen A, Bell DA, Lang NP, Kadlubar FF. Role of aromatic amine acetyltransferases, NAT1 and NAT2, in carcinogen-DNA adduct formation in the human urinary bladder. Cancer Res 1995;55:5230-7.

3. Minchin RF. Acetylation of p-aminobenzoylglutamate, a folic acid catabolite, by recombinant human arylamine $\mathrm{N}$ acetyltransferase and U937 cells. Biochem J 1995;307:1-3. 4. Sim E, Westwood I, Fullam E. Arylamine Nacetyltransferases. Expert Opin Drug Metab Toxicol 2007;3:169-84.
5. Rodrigues-Lima F, Cooper RN, Goudeau B, et al. Skeletal muscles express the xenobiotic-metabolizing enzyme arylamine N-acetyltransferase. J Histochem Cytochem 2003;51:789-96.

6. Dupret JM, Rodrigues-Lima F. Structure and regulation of the drug-metabolizing enzymes arylamine $N^{-}$ acetyltransferases. Curr Med Chem 2005;12:311-18.

7. Butcher N, Boukouvala S, Sim E, Minchin RF. Pharmacogenetics of the arylamine Nacetyltransferases.

Pharmacogenomics J 2002;2:30-42.

8. Hein DW. N-acetyltransferase 2 genetic polymorphism: effects of carcinogen and haplotype on urinary bladder cancer risk. Oncogene 2006;25:1649-58.

9. Boukouvala S, Fakis G. Arylamine N-acetyltransferases: what we learn from genes and genomes. Drug Metab Rev 2005;37:511-64.

10. Butcher NJ, Ilett KF, Minchin RF. Substratedependent regulation of human arylamine Nacetyltransferase-1 in cultured cells. Mol Pharmacol 2000;57:468-73.

11. Atmane N, Dairou J, Paul A, Dupret JM, RodriguesLima F. Redox regulation of the human xenobiotic metabolizing enzyme arylamine $\mathrm{N}$-acetyltransferase 1 (NAT1). Reversible inactivation by hydrogen peroxide. $J$ Biol Chem 2003;278:35086-92.

12. Dairou J, Atmane N, Dupret JM, Rodrigues-Lima F. Reversible inhibition of the human xenobioticmetabolizing enzyme arylamine $\mathrm{N}$-acetyltransferase 1 by S-nitrosothiols. Biochem Biophys Res Commun 2003;307:1059-65.

13. Dairou J, Atmane N, Rodrigues-Lima F, Dupret JM. Peroxynitrite irreversibly inactivates the human xenobiotic-metabolizing enzyme arylamine Nacetyltransferase 1 (NAT1) in human breast cancer cells. A cellular and mechanistic study. J Biol Chem 2004;279:7708-14.

14. Dairou J, Malecaze F, Dupret JM, Rodrigues-Lima F. The xenobiotic-metabolizing enzymes arylamine $\mathrm{N}$ acetyltransferases (NAT) in human lens epithelial cells: inactivation by cellular oxidants and UVB-induced oxidative stress. Mol Pharmacol 2005;67:1299-1306.

15. Rodrigues-Lima F, Dairou J, Dupret JM. Effect of environmental substances on the activity of arylamine $\mathrm{N}$ acetyltransferases. Curr Drug Metab 2008;9:505-9.

16. Wakefield L, Robinson J, Long H, et al. Arylamine Nacetyltransferase 1 expression in breast cancer cell lines:a potential marker in estrogen receptor-positive tumors. Genes Chromosomes Cancer 2008;47:118-26.

17. Adam PJ, Berry J, Loader JA, et al. Arylamine NAcetyltransferase-1 Is Highly Expressed in Breast Cancers and Conveys Enhanced Growth and Resistance to Etoposide in Vitro. Mol Cancer Res 2003;1:826-35.

18. Butcher NJ, Tetlow NL, Cheung C, Broadhurst GM, Minchin RF. Induction of human arylamine Nacetyltransferase type I by androgens in human prostate cancer cells. Cancer Res 2007;67:85-92.

19. Ragunathan N, Dairou J, Pluvinage B, et al. Identification of the xenobiotic-metabolizing enzyme arylamine Nacetyltransferase 
1 (NAT1) as a new target of cisplatin in breast cancer cells: molecular and cellular mechanisms of inhibition. Mol Pharmacol 2008;73:1761-8.

20. Ott I, Gust R. Preclinical and clinical studies on the use of platinum complexes for breast cancer treatment. Anticancer Agents Med Chem 2007;7:95-110.

21. Cullen KJ, Yang Z, Schumaker L, Guo Z. Mitochondria as a critical target of the chemotheraputic agent cisplatin in head and neck cancer. J Bioenerg Biomembr 2007;39:43-50.

22. Duman RK, Heath RT, Bose RN. Inhibition of Escherichia coli DNA polymerase-I by the anti-cancer drug cis-diaminedichloroplatinum(II): what roles do polymerases play in cisplatin-induced cytotoxicity? FEBS Lett 1999;455:49-54.

23. Shin JN, Seo YW, Kim M, et al. Cisplatin inactivation of caspases inhibits death ligand-induced cell death in vitro and fulminant liver damage in mice. J Biol Chem 2005;280:10509-15.

24. Hasinoff BB, Wu X, Krokhin OV, et al. Biochemical and proteomics approaches to characterize topoisomerase IIalpha cysteines and DNA as targets responsible for cisplatin-induced inhibition of topoisomerase IIalpha. Mol Pharmacol 2005;67:937-47.

25. Lee JH, Lu HF, Wang DY, et al. Effects of tamoxifen on DNA adduct formation and arylamines Nacetyltransferase activity in human breast cancer cells. Res Commun Mol Pathol Pharmacol 2004;115-116:217-33. 26. Kawamura A, Westwood I, Wakefield L, et al. Mouse $\mathrm{N}$-acetyltransferase type 2, the homologue of human Nacetyltransferase type 1. Biochem Pharmacol 2008;75:1550-60. 